This article consists of pp. 193 to 198 as reprinted from the Lawrence Berketey Laboratory Earth Sciences Division Ameal Report, 1978 (LBL-8648).

\section{STATISTICAL ANAIYSIS OF THE CORRELATION OF EARTHQUAKES WITH RADON CONCENTRATION IN WATER FROM SHALLOW WELLS NEAR OROVILLE, CALIFORNIA B. Berlin}

\section{INTRODUCT ION}

This ceport is an account of work performed f rom June 20 to September 25,1978 , funded by Lawrence Berkeley Laboratory Director's Development funds. This work is part of an investigation to deteraine whether a statistical relationship exists between varying radon coacentration in well waters and the occurrence of nearby earthquakes. If such a dependence is verified, then cert 3 in patcerns of changing radon activity may be useful for predicting earthquakes.

Radon concentration in two water wells near Oroville, California, the Prosise and the Gilley wells, were compared vith periodic aftershocks of the Auguat 1,1975, Oroville earthquake for a per lod of about 600 days. The data are consistent with data being generated from a distribution of: (a) all noise, or; (b) long-term selsalc : luctuations correlated with changes in the Prosise well, or short-term seismic fluctuations with changes in che Gilley well, or both. In both cases, the dependence must be expressed with different equations in different directions from the wells. Al so the data are inconsistent with data being generated from a distribution there the dependence between seismic activity and radon activity is very strong in all directions.

\section{DATA COLLECTION}

The collection of radon data started a fou days after the August 1, 1975, Oroville (California) earthquake of magnitude 6 on the Richter scale, and so coincides with the series of aftershocks. Sampling consisted of filling a pair of 500-ml-capacity polyethylene bottles at the llhead, sealing them imediately against gas loss, transporting them to LBL within a few days of collection time, and making direct measurement of the radon content of the vater by 1ow-leve 1 gamma-ray spectrometry at the LBL Low Background Counting Facility.

Ore sample per day was collected from each of six wells in the region of aftershock sccurrence, including wells drilled into poorly consolidaced sediments and into bedrock formations. The location of these wells is given in Figure 1. Subsequent experience showed that only bedrock wells showed a significant radon variation. Sampling at other wells was then curtailed, and our efforts concentrated on acquiring detalled data frox three bedrock wells. The shallorest of these (the vorman rell, 65-tit deep) is belleved to have suffered occasional Invasion of Irrigation water applied to nearby pasture land. Data fror thIs ve II are therefore of questionable value. Data trom the two remaining bedrock wells (the Gilley and Prosise wells, each about $200-\mathrm{ft}$ deep and dedicated to domestic use only) cover the time from August 12, 1975. co April 6, 1977-a seretch ef 602 days. For each of these vells, there are fewer than 15 days of missing observations. values vere simulated for the nissing days by inear or cubic interpolation fror neighboring values. Typlcal data obtal ned from the Gilley and Prosise wells are 11 lustrated in rure 2 .

.he seiseic data inctude earthquake time (to the second), epicenter coordinates, depth, and Richter agnitude. This information was obtained from tists comiled by the Califomia State Department of Hater Resource (GHR), Sacramento, Califomia, an: the Uniced States Ceological Survey National Centrr for Earchquake Research (USCS), Henlo Park, Califormiz.

\section{STATIST ICAL. AKALYSIS}

Tne objective is to deasure the extent to wich variations in the earthquake process (time, magnitude, distance from wel1s) are correlated vith changes in radon activity. The technique used is described in detail by Brillinger (1975). A more elementary introduction to this topic is given by Rendall (ja73).

\section{ROTATION AND MODEL.}

Time is discretized in days. That is, both radon sampling times and earthquake event $t$ imes are truncated to the nearest day. The days are numbered: $t=1,2,3, \ldots, t=600$. Th? number of days studied, 600 , vas chosen becauscomputations involved in the analysis are much less time-consuming then $N$ can be factored in many small primes $\left(600=2^{3} .3 .5^{2}\right)$.

Earthquake e.ta are thought of as the vependent variable there: $Y_{1}(t)=1$ if an earthquake occurs on day $t$, and where $\mathrm{Y}_{1}(t)=0_{3}$ if not. It would have been very desirable to deal simul taneously with the epicenter-vell distance, chus: $Y_{2}(c)=$ $1 /$ distance, if the earthquake occura on day $r$, 


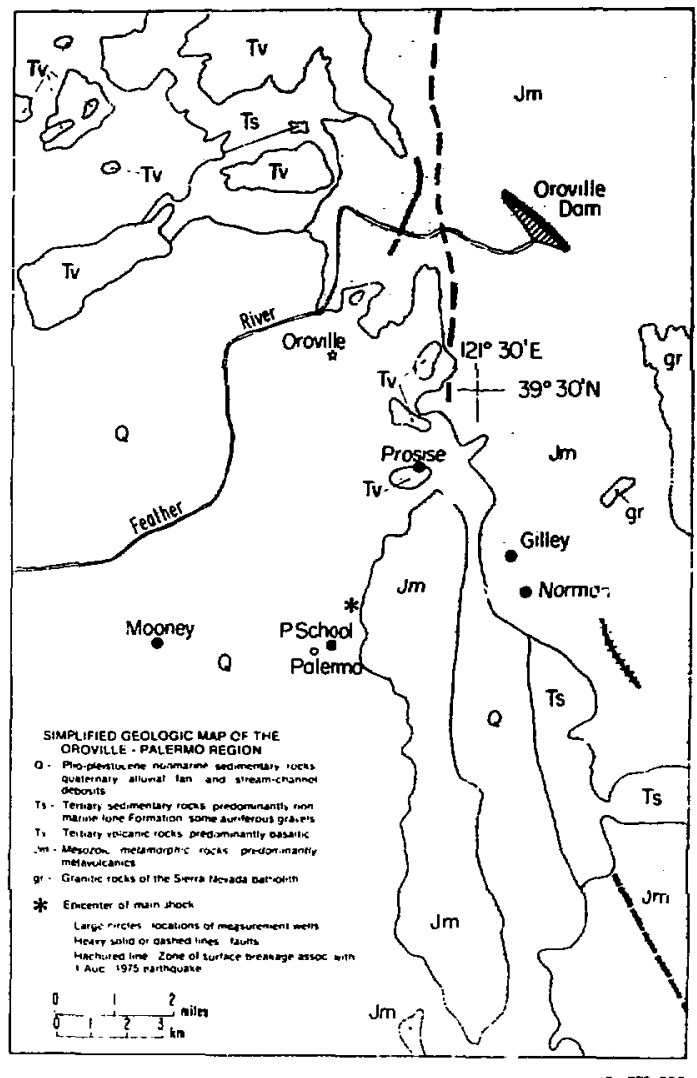

Figure 1. Simplified map of the Oroville, Califcrnia, area, showing surface geology and the locations of sampled wolls in relption to the August 1, 1975, earthquake.

and $Y_{2}(t)=0$, if not. However, a problea ar ises here because $Y_{2}=0$ usually weans that there was no earthquake. In the assumed model, $Y_{2}=0$ ia confused with having a very distant earthquake; therefore, $Y_{2}$ is not used.

The appropriate nodel for aimultaneous andyoia of occurrence, location, and magnitude is marked-point process in thich the distribution of the location and magnitude is defined only when earthquake occurs.
W: 11 data are the independent variable where:

$$
\begin{aligned}
& x_{1}(t)=\text { racon activity in Prosise on day } t ; \\
& x_{2}(t) \text { - radon activity in Gilley on day } t ;
\end{aligned}
$$

Many subsets of earthquakes have been fitted to models of the following type:

$Y(t)=Y_{1}(t)$, and $\underline{X}(t)=\left[X_{1}(t), X_{2}(t)\right]$. 


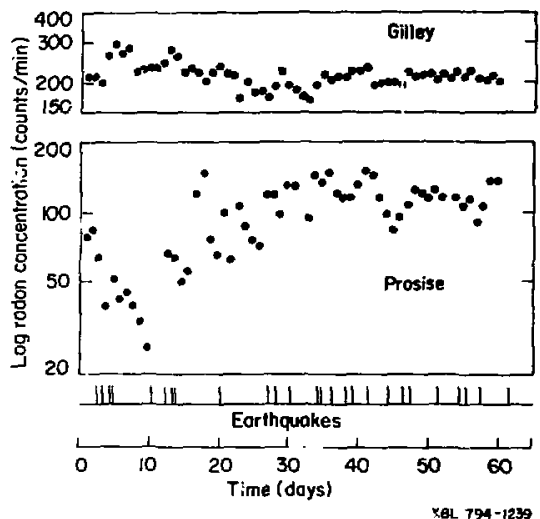

Figure 2. Typical data from the Gilley and Prnoise wells for the period October co November 1975, showing daily radon activity and the occurrence $t$ imes for $a 11$ earthquakes with magnitudes greater than $\sim 2$ on the Richter scale.

Thes are assumed to be stationary tine series. Therefore, we can conclude the following.

The expected values of $Y(c)$ and $X(c)$ remain constant in tirse, so that fluetuatioñ are observed to occur about a fixed mean level. This is, scrictly speaking, false. Both the seismic activity and the radon measurewents in the two wh show trends. Linear components of all trends have been removed as a first step to treat the data. Although the rate of seismic events decreases, as during the time interval studied, radon activicy in the Prosise well shows a positive trend and for the Gilley well it is negative. The change in average radon level is considerable. The Prosise radon level is $40 \%$ higher toward the end of the 600-day period compared with the beginning; for the Gilley well the decrease is also 407 over the same time period. The removal of such a trend is a concession that only changes can be analyzed, for which several cycles are observed in the 600 days available.

Any dependence within and between processes relates only to the length of time between the two points considered, rather than to their absolute location on the time scale. Thus, February and April of 1976 are assumed to ho so strrngly related as September and November of 1977 (two months apart in both cases).

These assumptions zre expressed in terms of the covar iances:

$\operatorname{Cov}\left\{x_{i}(t), x_{j}(t+u)\right\}=c x_{i}, x_{j}(u)$

for all $t, i, j=l, 2$
$\operatorname{Cov}[Y(t), Y(t+u)]=G_{Y Y}(u)$

for all $t, 1, j=1,2$

$\operatorname{Cov}\left(Y(t), X_{j}(t+u)\right)=c_{X_{j}} Y^{(u)}$

for all $t, i, j=1,2$.

The codel comeonly used to relate $Y$ and $\underline{X}$ is linear:

$$
Y(r)=\mu+\sum_{\nu=-\infty}^{+\infty} \underline{a}(u) \underline{x}(\tau-u)+c(t),
$$

meaning that the probability of an earthquake on day $t$, given a particular pattern of $\underline{t}$ around $t$, is:

$$
i+\sum_{i=-\infty}^{+\infty} a(u) \underline{x}(t-u)
$$

"Here, $\nu$ is the long-ters probability of an earthquake, and $a(u)$ is a function of the time lag $u$. For each $u=0, \pm 1, \pm 2, \ldots ., a(u)$ is a vector with two elenents of uninom constants and $\varepsilon(t)$ is the error aeries, which also is stacionary. If the variacions in $Y$ are well accounted for by equation (1) for aome values of $\mu$ and $a(u)$, then the variation in $r(t)$ will be considerably less than in $Y(t)$. Note that when $u$ is allowed to assume values smaller than zero, the future of $X$ (beyond $t$ ) is involved, so a good fit for equation (1) does not necessarily imply that a prediction based on pest $x$ only vill be successful.

Equatior. (1) is reminiscent of multiple linear regression, but here observations are correlated even when they are made at different times. This complicates the analysis quite a bit; statisticians prefer to work with Fourier cransforms of the series and their covar $j$ ance functions because it is wach easier co derive criteria to check if any patterns in the data are statisticslly significant, that is, if they are unlikely to have arisen on ly from random noise. In the covariance functions given above, dependence is described for observations $u$ days apart. The Fourier transforms of these functions tell the same message, but che argument is a Erequency $\lambda$, racher than the time lag $u$. In Fourier analysis, the time series is decomposed in a linear combination of many trigonometric functions (sines and cosines) of vacying amplitudes. The different cowponents have frequencies varying between 0 and $\pi$, where the highest frequency corresponds to $u=1$, or cycles of 1 day. Here $u$ and $\lambda$ correspond to the same wave and are inversely proportional.

\section{DISCUSSION OF RESULTS}

Spectra for radon dala alone reveal two things. First, the long-term variations (periods greacer than 15 days) have much larger anplitude than components with periods of a few days. This phenorenon appears despite the fact that d linear trend has been rewoved. Second, 
the correlation between the two wells is negligible. This suggesto that any effect that increased stress has on radon activity is very local. The $11 \mathrm{~s}$ are $3.7 \mathrm{~km}$ apart.

It is more difficult to find a consistent pattern in the earthquke spectra. Whereas each atcempt to fit the data involvea the colplete Bet of well observations, the set of selected earthquakes changes. This is done by including a 11 earthquakes within sowe diatance of the wel1 considered.

Also, only earthquakes with magnitude greater than 1.5 are included. For some selections, there is a tendency for the events to occur in cycles; $i$ other sases the estimated dependence is weak, more like a Poisson process. This is a matter to which little attention has been given during this search for a relation between earthquakes and radon data. It is worth furfher investigation.

Finally, we considered the dependence betveen oeismic events and radon activicy. The extent to which the data fit the podel (equation 1) is measured by the coherence $\mathbf{R}_{\mathrm{FX}}(\lambda)$, a generalization of the usual correlation coefficient used in simple linear regression. For a particular $\lambda$, it measures the dependence of the trigonometric wave in earthquake occurrence (frequency) on the linear expression of radon data, as in equation (1).

Looking first at the vicinity of the Prosise we 11, all earthqukes were picked within radii of 2,3 , and $4 \mathrm{~km}$. In each case, the estimated coherence was low enough to be consistent with no dependence at all. Thereafter, senicircles and quadrants were tried with $3-k m$ radii, or a total of eight different tests. In two cases the coherence agsumed significant values. These are presented in Figure 3 .

\begin{tabular}{|c|c|c|}
\hline 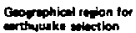 & $\max R_{x y}^{2}|\lambda|$ & 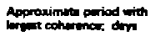 \\
\hline
\end{tabular}
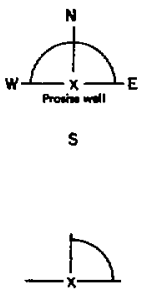

D. 17

20 of course, the criterin for a significance are calculated for ane perticular cun. Where any atatiotical teate are tried, the significence statement: lowe their power for dravine conclusions. Rather, atcentisn is dran here to the subsets of exthquakes vith the highest correlation, vithout atating that it vill hold up in the long run.

Likewise for the Gilley wil, the earthquakes within circles how faint dependence with the radon date. The ane is true for sericirclee.

Quadrant: look better, an shoun in Figure 4. Hote that $\mathrm{R}^{2} \mathrm{xy}(\lambda)=0.16$ is the 57 rejection linit. Why do all four quadrants shou sose dependence, but none of the sericircles? The reason is that the bet ficting constants $[a(u)$ in equation ( 1$)]$ are quite different for the four quadrants, and compromise yalues necessary for exicircle fail to explain the variation in seivie activity.

Figure 5 is a plot of $a(u)$ v. u for the four quedrant zones around the Gilley well that showed we prosise with reapect to coherence. The horizontal y-axis has been reversed, putting negative u's to the right. The edrantage ia that the positive u" (corresponding to preceding days) vill be to the left of the origin. The plots of $a(u)$ all hor strong oscillations from high to low values. What does this genn? A firat idea would be to reconatruct what pattern of radon changes aakes the ripht-r.and

\begin{tabular}{|c|c|c|}
\hline Gopraphion revion tor & $\max A^{2} x y^{\prime}(\lambda)$ & 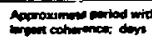 \\
\hline
\end{tabular}

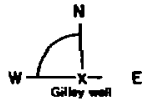

$11 / 4$

$\mathbf{S}$

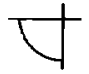

0.27

114

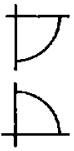

0,33

$12 / 3$ to 2

n?

$11 / 2$
Figure 3. Geographical sulections of selsmic events within a 3-km radius of the Prosise wel.1 showing the correlution between selsmicity and radon activity.
F1gure 4. Geographical selections sif sefomic events wthin a $3-\mathrm{km}$ radius of the Gilley well showing the correlation between seismicity and radon activity. 


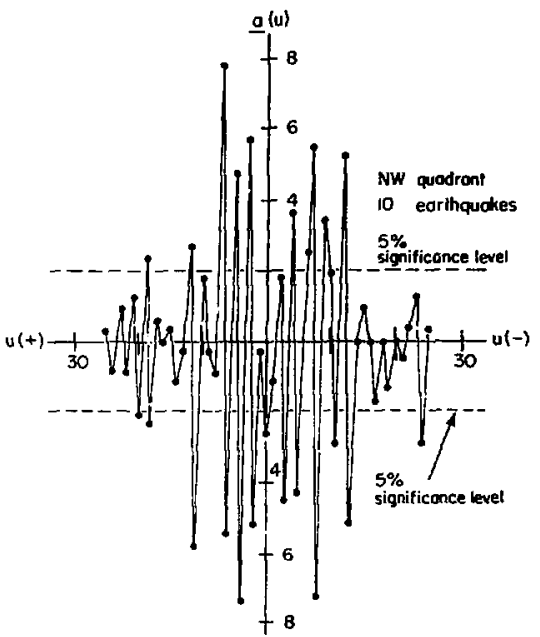

XBL $794-1243$

Figure 5. Profile of values for the constant a(u) in equation (1), computed for the $3-\mathrm{km}$ radius quadrant northwest of the Gilley well. Previotis days are plotted to the left of the origin; future days, to the right. The ordinate scale is in terms of the estimated etandard deviation on $a(u)$ values.

side of equation (1) large for the given estimated a(u). That is, what makes the chance for an earthquake large? Also, what pattern makes the chance sinall?

Obviously, a day with a large positive a(u) calls for a positive radon count to contribute to a large probability. If a $(u)$ has a large negative value, the radon count should be unusually small. Therefore, a strongly oscillating radon pattern would serve as a precursor. Further, an oscillacing pattern out of phase with the former type would be an "antiprecursor" and make the chance small.

However, this idea is a dead end because the radon record simply does not have any such rapid oscillations. As mentioned earlier, the variation in radon activity is doninated by slow oscillations.

A more believable interpretation of the rapid fluctuations of $g(u)$ is that the predictive effect of radon changes is very short rerm, about 1 to 2 days.

Erom the point of view of earthquake prediction, the long-tern variations with large anplitude are noise that mat be filtered away by the coefficients $a(u)$. This is actually ach ieved with high and 20 al(u) following each other.

An object for further investigatial is to study the quickly varying radon aignal that remains after filtering, wich accully serves as a precursor.

The conbined predictive ability for the two wlls was atso tried by seleccing earthqukes within ellipses that had the welis as foci, as illuerated in Figure $6(s)$.

As expected from the wak dependence of the two radon series, it curned out that for these subsets, the Prosise wellfhad negligible dependence with the earthquakey, wile the largeat coherence observed so far; occurred between the

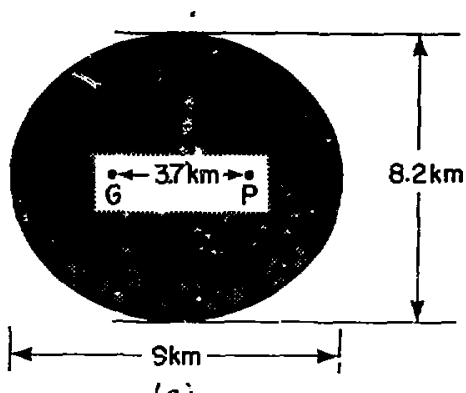

$10 j$
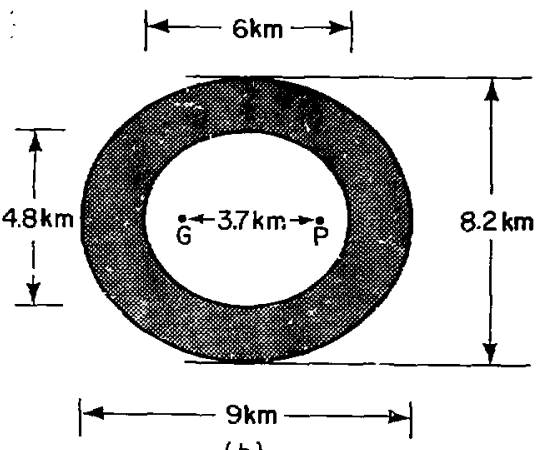

(b)

XBL $794-1242$

Figure 6 . Configurations to test the combined predictive abilicy for prosise and Gilley wells (shaded areas indicate regions in wich earthquakes occurred). 
Gilley well and the earthquakes. Ellipaes of difierent sizes were tried and the fit improves further if an inner ellipse is excluded, as show in Figure 6(b).

Further work should be done to identify more reasunable looking zone where the Gilley well is rensitive. The substantial coherence appeared at a frequency corresponding to a period of 2-1/2 days.

\section{RECOMRENDATIONS}

To put the above inconcluaive findings to a test, we recomend the following.

More data are needed, particularly fron the Gilley well, which appears most prowiaing. In the present data, the radon samples are not exactly 24 hours apart; they were taken at different times in the afternoon. To check the one- to four-day fluctuations, it would be useful to have radon activicy recorded at exact 12-hr intervals.

Hith the statiatical nethods used here (continuous time gerieg) there is no satisfactory way to take epicenter-to-sell distance and magnitude into account simulteneously, as pointed out earlier with regard to the variable $Y_{2}$. A statistical method relating a markedpoint process to a continuous time series should be developed.

It is useful to test the radon data against a model in which two types of earthquake precursors are postulated:
1. Signals whose appenrance in prior-tive are related to the angitude of an ipending earthquake--ignals that ary enccopas the tive domain of daje to reara

2. Signals whose appearance in prior-tine are unrelated to the monitude of an impending earthquake-aignals that wy encompat the tine dorein of hours to a feu daye (foreshocke)

The atatiotical wethod eployed bere should be ell suited for identifying precursore of the second kind-those that occur at (relatively) fixed tine before an earthquake. However, in its present fore, the ethod is not wil suited for identifying precursors of the firat kind-those that any occur over a few daye to a few 10s of days for the aftershock angnitudes encountered during the Oroville study. Hence. adepting the preaent wethod or adopting none other approach, in important in order to include $t$ ine/ongnitude/diatance paraneters for individual earchquakes in the analyois procedure.

\section{REFERERCBS CITED}

Brillinger, D. R., 1975. Time series, data anlysis, and theory. Hew York, Holt, Rinehart and Winston

Kenda L1, H. G., 1973. Time series. NeU York, Griffin.

Work supported by Department of Energy. 